\title{
Spontaneous Variations in Resting Blood Flow, Postischaemic Peak Flow and Vibratory Perception in the Feet of Diabetics
}

\author{
N.J. Christenshen
}

Sec ond Clinic of Internal Medicine, Kommunehospitalet, Århus University School of Medicine, Århus, Denmark

Received: August 30, 1968

Summary. The variability of the resting blood flow in the foot was studied by means of venous-occlusion plethysmography in 25 diabetics and 16 non-diabetics. To evaluate the functional state of the vessels themselves, the postischaemic peak flow was studied in the same patients. To obtain an estimate of the functional state of the nerves the vibratory perception threshold was determined. - The following results were obtained: 1 . The normally occuring spontaneous variations in the resting blood flow in the foot were considerably reduced in the diabetic group of patients, although the mean resting blood flow was identical in the diabetic and the nondiabetic group. The lack of spontaneous variations showed a strong association with the duration of diabetes. -2 . The peak flow was often reduced in long term diabetic patients. This abnormality was associated with the presence of arterial calcifications. - - 3. The vibratory perception threshold increased with increasing duration of diabetes as already shown by other authors. - 4. It was demonstrated by statistical analysis that the loss of rhythmic activity in the resting blood flow was due to autonomic neuropathy as well as to a vascular factor.

Variations spontanées du débit sanguin au repos, du clocher post-ischémique et de la perception vibratoire dans les pieds de diabétiques

Résumé. La variabilité du débit sanguin au repos dans le pied a été étudiée à l'aide de la pléthysmographie par occlusion veineuse, chez 25 diabétiques et 16 non-diabétiques. - Pour évaluer l'état fonctionnel des vaisseaux eux-mêmes, le clocher du débit post-ischémique a été étudié chez les mêmes patients. Pour obtenir une estimation de l'état fonctionnel des nerfs, le seuil de perception vibratoire a été déterminé. - Les résultats suivants ont été obtenus: 1 . Les variations spontanées du débit sanguin au repos qui se produisent normalement dans le pied étaient considérablement réduites dans le groupe diabétique, tandis que le débit sanguin moyen au repos était identique dans le groupe diabétique et nondiabétique. L'absence de variations spontanées était en forte corrélation avec la durée du diabète. - 2. Le clocher du débit était souvent réduit chez les patients diabétiques depuis longtemps. Cette anomalie était associée à la présence de calcifications artérielles. - 3. Le seuil de perception vibratoire augmentait avec l'augmentation de la durée du diabète, comme l'ont déjà indiqué d'autres auteurs. 4. Il a été démontré par l'analyse statistique que la perte de l'activité rythmique du débit sanguin au repos était due à la neuropathie autonome aussi bien qu'à un facteur vasculaire.

Spontanschwankungen der Ruhedurchblutung, der postischaemischen Maximaldurchströmung und des Vibrationsempfindens am Fuß von Diabetikern

Zusammenfassung. Die Schwankungen der Ruhedurchblutung des Fußes wurden bei 25 Diabetikern und 16 stoffwechselgesunden Kontrollpersonen durch venöse Okklusions-Plethysmographie untersucht. Außerdem wurden bei den gleichen Probanden die postischaemische Maximaldurchblutung und die Reizschwelle des Vibrationsempfindens bestimmt, um den funktionellen Zustand der Gefäße und Nerven beurteilen zu können. - Diese Untersuchungen führten zu folgenden Ergebnissen: 1. Die normalen Spontanschwankungen der Ruhedurchblutung des Fußes waren bei den Diabetikern beträchtlich reduziert, obgleich die Ruhedurchblutung selbst bei der Grup. pe der Diabetiker und der Normalpersonen übereinstimmte. Das Fehlen der Spontanschwankungen war mit der Diabotesdauer korreliert. - 2. Bei Langzeitdiabetikern fand sich häufig eine verringerte Maximaldurchblutung bei vermehrtem Nachweis arterieller Gefäßverkalkungen. - 3. Der Schwellenwert für das Vibrationsempfinden stieg parallel zur Dauer der diabetischen Erkrankung an, wie von anderen Autoren bereits demonstriert worden ist. - 4. Durch die statistische Auswertung ließ sich nachweisen, daß die fehlenden Spontanschwankungen der Ruhedurchblutung sich sowohl auf eine autonome Neuro. pathie als auch auf einen Gefäßfaktor beziehen lassen.

Key-vords: Spontaneous variations, resting blood flow, postischaemic peak tlow, vibratory perception, feet, diabetics, arterial calcification, autonomic neuropathy.
During studies designed to examine blood flow in the feet of diabetics, it was noted that the so-called spontaneous variations in the resting blood flow were often absent or considerably reduced in diabetic patients.

The present study was undertaken to evaluate various aspects of this abnormality, particularly to clarify whether the abnormality is due to autonomic neuropathy, or to a lesion of the vessels themselves. The degree of nerve lesion was estimated by measuring the vibratory perception threshold in the big toe, and the functional state of the vessels was evaluated by studying the vascular response to artificially induced ischaemia, viz. the peak flow. The interrelationships in individual patients between these two parameters, and the variability of the resting blood flow were analyzed.

\section{Methods}

The blood flow in the foot was measured by venousocclusion plethysmography.

The foot plethysmograph used in the present study had a general design similiar to the apparatus described by ST'AD and KUNKEL [32], and the technical data need therefore not be reported in detail. The expansion chamber at the upper surface of the plethysmograph, 
which was connected with the registration apparatus, had a surface area of $21 \mathrm{~cm}^{2}$.

The plethysmograph was waterfilled, and the water temperature thermostatically controlled at $32^{\circ} \mathrm{C} \pm$ 0.2 [6]. An ink writing piston recorder was used for registration.

The opening of the plethysmograph through which the limb passed was closed by a thick $(5 \mathrm{~mm}$ in thickness) and a thin rubber diaphragm. The thin diaphragm was attached to a rubber cuff, which was cemented to the skin just proximal to the malleoli. The diaphragms were pressed against the opening of the plethysmograph by an iron ring. The diaphragms and the cuff were made individually on the basis of a plaster-ofParis bandage casting of the region just proximal to the malleoli.

The calibration was done during arrest of the circulation by injecting two $\mathrm{ml}$ of water in successive steps and measuring the mean rise of the pen.

The volume of the enclosed foot was obtained by measuring the amount of water in the plethysmograph at the end of the experiment and subtracting this amount from the known volume of the apparatus.

A blood pressure cuff $6 \mathrm{~cm}$ wide was applied to the leg just above the ankle, and a pressure of $50 \mathrm{~mm} \mathrm{Hg}$ was used for venous occlusion [34].

A quantitative estimate of somatic nervous function was obtained by measuring the vibratory perception threshold in the big toe. The vibratory perception threshold was measured with a standardized technique [33] by a biothesiometer ${ }^{1}$ and expressed in volts. Other procedures included palpation of the dorsal pedal artery and the posterior tibial artery, and measurement of blood pressure.

X-ray films of the foot (dorsal-plantar and lateral films) were taken with the specific technique for demonstrating arterial calcification.

The patients were studied in a quiet room. The temperature of the room was controlled at $23^{\circ} \mathrm{C}$ (range $22-24^{\circ} \mathrm{C}$ ). The blood flow was measured while the patient was resting comfortably in the horizontal position covered by two blankets. The patients were at rest, with the foot enclosed in the plethysmograph for at least $30 \mathrm{~min}$ before blood flow measurements were started.

Blood flow measurements were performed in the following manner: The resting blood flow was measured as quickly as possible approximately 30 times. This procedure lasted about $8 \mathrm{~min}$. The circulation in the foot was then stopped by inflating the blood pressure cuff with a pressure of $300 \mathrm{~mm} \mathrm{Hg}$. The arterial occlusion was maintained for $6 \mathrm{~min}$ and then suddenly released. The blood flow was measured as often as possible during the first minute, and approximately 4 times every minute until $9 \mathrm{~min}$ had elapsed, by which time the blood flow had returned to the preocclusion level. The whole procedure was then repeated until 4 series Ohio. of resting blood flow measurements and 3 or 4 series of flow values after arterial occlusion had been obtained. The investigation lasted for about 3 hours, and included approximately 250 blood flow determinations in each patient.

The mean blood flow, the standard deviation and the coefficient of variation ${ }^{2}$ were calculated for each series of resting blood flow measurements, and the mean of the four series used in the analysis presented in the following. In four patients, however, only 1 or 2 series were available.

The flow values obtained during reactive hyperaemia were plotted into a coordinate system where the shape of the hyperaemic curve could be studied. The maximal blood flow, which generally occured within the first minute after release of the arterial occlusion, was measured. The peak flow was calculated by subtracting from the maximal blood flow the mean resting blood flow measured in the 8 minute period immediately before arterial occlusion.

Conventional probability levels of significance have been used in the statistical analysis, a $P$ value greater than 0.05 not being considered significant.

\section{Patients}

41 individuals were studied. 25 were diabetics, 15 males and 10 females. The mean age was 36 years (range 27-48 years). The duration of diabetes ranged between $0-40$ years, and was more than 20 years in approximately half of the diabetic patients. One fourth of the patients had clinical neuropathy in the sense of pain and paraesthesiaes. 16 individuals were nondiabetics. None of them had symptoms of diabetes mellitus or glucosuria. The mean age was 38 years (range 26-46 years). 10 were males and 6 females. Diabetics and non-diabetics were examined at random.

The variability of the resting blood flow was also studied in three, newly-diagnosed juvenile diabetics during metabolic derangement and after normalization of the blood sugar. Two series of resting blood flow measurements were obtained before and after careful treatment with insulin.

\section{Results}

All important data are summarized in Table 1.

Resting blood flow. In the non-diabetic group the mean resting blood flow averaged $3.7 \mathrm{ml}$ per $100 \mathrm{ml}$ foot per min. $\pm 1.1 \mathrm{ml}$ (range $2.1-6.5 \mathrm{ml}$ ). No association with age could be demonstrated.

In the diabetic group the mean resting blood flow averaged $3.9 \mathrm{ml}$ per $100 \mathrm{ml}$ foot per min. $\pm 1.3 \mathrm{ml}$ (range 1.9-6.7 $\mathrm{ml}$ ). The resting blood flow in the diabetic group showed no association with the age of the patient, the duration of the disease, the vibratory perception threshold or the peak flow. Neither the

\footnotetext{
2 standard deviation $\times 100$
} 
mean blood flow nor the range in the two groups differed significantly from each other.

Variability of the resting blood flow. In the nondiabetic group of patients the resting blood flow was varying continuously. Sometimes even differences in the slope of single inflow curves were seen. The change in flow often occured in waves. Fig. 1 demonstrates a

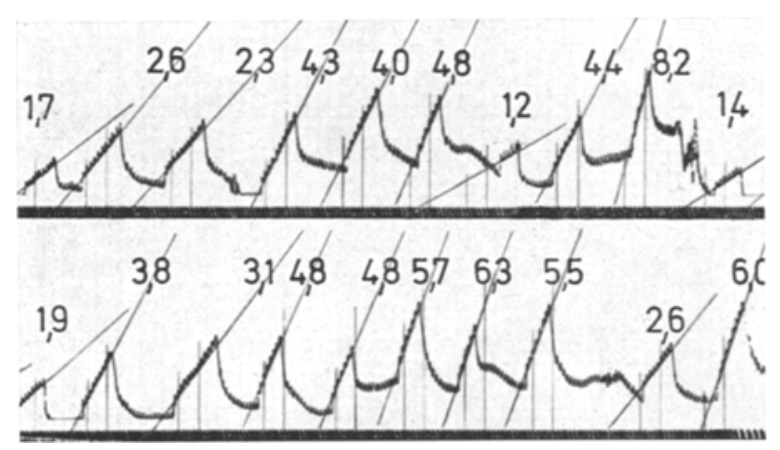

Fig. 1. The figure represents a section of one of the series of resting blood flow measurements obtained in a nondiabetic (Case No. 27). Note the undulating change in arterial inflow. Time marker: 11 units $=10 \mathrm{sec}$

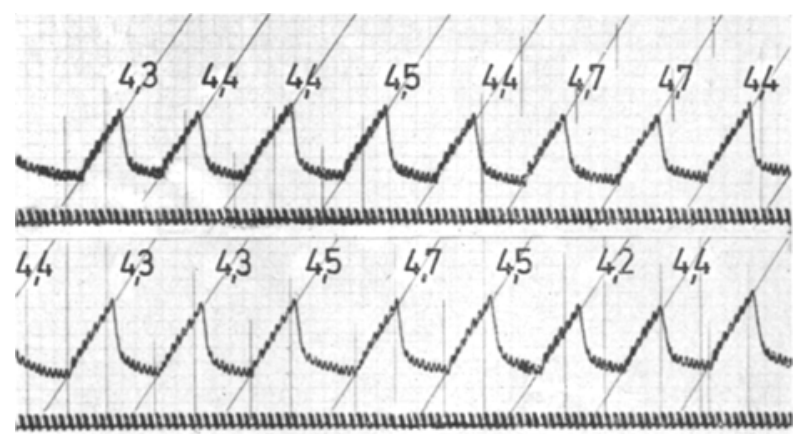

Fig. 2. The figure represents a section of one of the series of resting blood flow measurements obtained in a diabetic patient (Case No. 24). Note loss of spontaneous variations. Time marker: 11 units $=10 \mathrm{sec}$

section of one of the series obtained in Case No. 27. The amplitude of variations, expressed as the standard deviation, increases with increasing mean resting blood flow. The equation of the regression line is:

$$
y=0.29 x+0.13
$$

and the regression coefficient differs significantly from zero ( $P$ less than 0.02 ). The coefficients of variation are, however, independent of the mean resting blood flow within the range of flow obtained here ( $P$ greater than 0.1$)$ and average $33(19-55)$. For this reason this parameter was used in the following analysis.

It appears from Table 1 that the variability in the resting blood flow was considerably reduced in many diabetics. This abnormality is illustrated in Figure 2, which represents a section of one of the series obtained in Case No. 24. Fig. 3 illustrates the difference in the temporal pattern observed in non-diabetics and diabeties. The upper graph shows a diabetic (॰) and a non- diabetic (o) (Case No. 10 and 15), whose average blood flow was approximately $4 \mathrm{ml}$ per $100 \mathrm{ml}$ foot per min. The lower graph shows in the same way the pattern in two cases (No. 5 and 26) where the average flow was somewhat lower, about $3 \mathrm{ml}$ per $100 \mathrm{ml}$ per min. The difference between the two patterns is quite striking, and it is obvious that the normally occuring sponta-

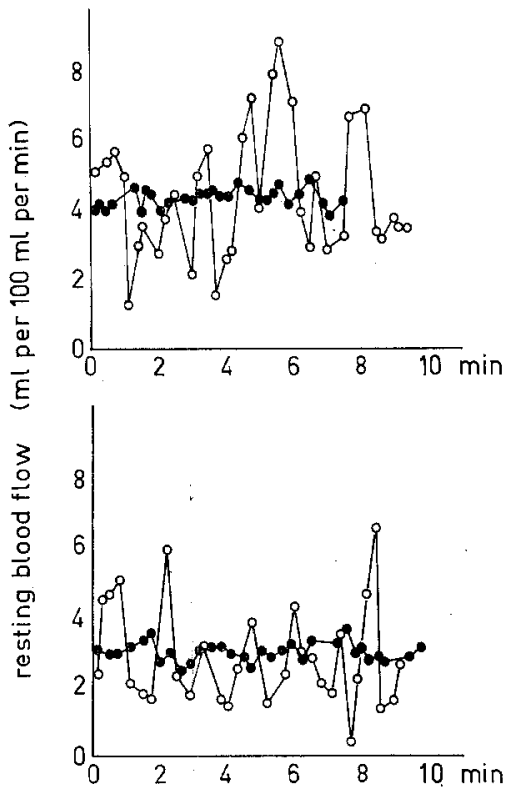

Fig. 3. The figure illustrates the difference in the temporal pattern observed in non-diabetics and diabetics. The upper graph shows a diabetic (॰) and a non-diabetic (o), whose average blood flow was approximately $4 \mathrm{ml}$ per $100 \mathrm{ml}$ foot per min. The lower graph shows in the same way the pattern in two cases where the average flow was about $3 \mathrm{ml}$ per $100 \mathrm{ml}$ foot per min

Table 1 a

\begin{tabular}{|c|c|c|c|c|c|}
\hline \multicolumn{6}{|c|}{ Non-diabetics } \\
\hline $\begin{array}{l}\text { Patient- } \\
\text { number }\end{array}$ & age & $\begin{array}{l}\text { resting } \\
\text { blood. } \\
\text { flow }\end{array}$ & $\begin{array}{l}\text { coefficient } \\
\text { of varia- } \\
\text { tion }\end{array}$ & $\begin{array}{l}\text { t peak } \\
\text { flow }\end{array}$ & $\begin{array}{l}\text { vibratory } \\
\text { perception } \\
\text { threshold }\end{array}$ \\
\hline 3 & 26 & 3.7 & 55 & 10.4 & 4 \\
\hline 7 & 36 & 4.1 & 27 & 10.7 & 12 \\
\hline 8 & 33 & 3.1 & 34 & 9.9 & 8 \\
\hline 10 & 37 & 4.0 & 33 & 9.2 & 9 \\
\hline 11 & 30 & 4.7 & 32 & 8.4 & 10 \\
\hline 12 & 29 & 2.1 & 19 & 10.1 & 8 \\
\hline 19 & 32 & 2.7 & 55 & 9.4 & 10 \\
\hline 22 & 41 & 3.6 & 26 & 10.1 & 9 \\
\hline 25 & 41 & 3.8 & 22 & 9.2 & 11 \\
\hline 26 & 46 & 2.9 & 44 & 13.2 & 12 \\
\hline 27 & 42 & 4.0 & 45 & 13.7 & 8 \\
\hline 28 & 44 & 2.8 & 38 & 9.3 & 18 \\
\hline 30 & 43 & 6.5 & 26 & 11.6 & 13 \\
\hline 31 & 43 & 3.7 & 19 & 9.4 & 14 \\
\hline 35 & 40 & 2.2 & 19 & 10.8 & 11 \\
\hline 39 & 42 & 4.8 & 33 & 10.8 & 10 \\
\hline
\end{tabular}

neous variations were greatly diminished in the two diabetic patients.

In Fig. 4 the coefficients of variation obtained in the 25 diabetic patients have been plotted against the 
duration of the disease. It appears that the variability decreased as the duration of the disease increased ( $P$ less than 0.01 , median test by chi square). This asso- cantly from the corresponding mean in the non-diabetic group ( $P$ less than 0.02 , Mann-Whitney $U$ test).

Table $1 \mathrm{~b}$

\begin{tabular}{|c|c|c|c|c|c|c|c|}
\hline \multicolumn{8}{|c|}{ Diabetics (duration less than 20 years) } \\
\hline $\begin{array}{l}\text { Patient- } \\
\text { number }\end{array}$ & age & $\begin{array}{l}\text { dura- } \\
\text { tion }\end{array}$ & $\begin{array}{l}\text { resting } \\
\text { blood } \\
\text { flow }\end{array}$ & $\begin{array}{l}\text { coefficient } \\
\text { of varia- } \\
\text { tion }\end{array}$ & $\begin{array}{l}\text { peak } \\
\text { flow }\end{array}$ & $\begin{array}{l}\text { vibratory } \\
\text { perception } \\
\text { threshold }\end{array}$ & $\begin{array}{l}\text { severe } \\
\text { calci- } \\
\text { fication }\end{array}$ \\
\hline 4 & 27 & 0 & 2.5 & 29 & 8.4 & 5 & \\
\hline 6 & 27 & 8 & 5.4 & 7 & 9.0 & 40 & \\
\hline 13 & 40 & 13 & 3.6 & 61 & 12.3 & 9 & \\
\hline 14 & 28 & 4 & 2.9 & 40 & 10.5 & 10 & \\
\hline 17 & 31 & 11 & 2.1 & 42 & 13.2 & 20 & \\
\hline 20 & 28 & 16 & 4.9 & 31 & 7.6 & 13 & \\
\hline 21 & 38 & 6 & 2.9 & 43 & 11.9 & 11 & \\
\hline 24 & 35 & 14 & 5.0 & 7 & 13.7 & 46 & \\
\hline 29 & 42 & 19 & 4.5 & 10 & 6.0 & 47 & \\
\hline 33 & 42 & 12 & 3.9 & 34 & 8.4 & 15 & \\
\hline 34 & 48 & 6 & 4.6 & 31 & 8.6 & 20 & \\
\hline 37 & 41 & 9 & 4.7 & 26 & 11.1 & 13 & \\
\hline 40 & 36 & 16 & 4.0 & 29 & 7.1 & 14 & \\
\hline \multicolumn{8}{|c|}{ Diabetics (duration greater than 20 years) } \\
\hline 1 & 38 & 24 & 2.3 & 11 & 10.2 & 40 & \\
\hline 2 & 37 & 35 & 3.0 & 5 & 0.6 & 50 & $X$ \\
\hline 5 & 33 & 26 & 3.3 & 10 & 8.4 & 43 & \\
\hline 9 & 29 & 28 & 3.1 & 21 & 5.2 & 28 & $X$ \\
\hline 15 & 40 & 27 & 4.7 & 9 & 4.4 & 47 & $X$ \\
\hline 16 & 37 & 22 & 4.8 & 28 & 11.4 & 13 & \\
\hline 18 & 42 & 21. & 3.6 & 16 & 2.8 & 23 & $X$ \\
\hline 23 & 43 & 40 & 6.7 & 16 & 3.2 & 12 & \\
\hline 32 & 38 & 28 & 1.9 & 22 & 8.4 & 23 & $X$ \\
\hline 36 & 32 & 27 & 2.3 & 8 & 3.4 & 41 & $X$ \\
\hline 38 & 40 & 22 & 5.5 & 7 & 3.9 & 17 & $X$ \\
\hline 41 & 38 & 36 & 6.3 & 14 & 4.6 & 13 & $X$ \\
\hline
\end{tabular}

Table $1 \mathrm{a}$ and $\mathrm{b}$. See text for explanation. $X$ denotes the presence of severe arterial calcification

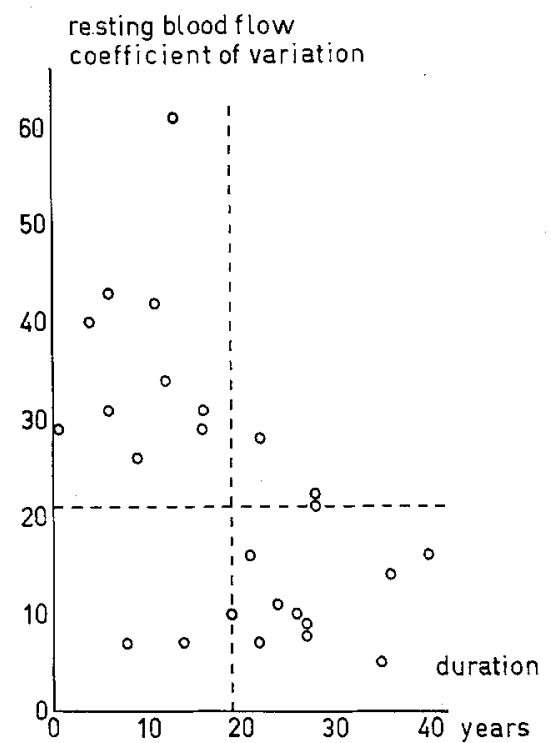

Fig. 4. The coefficient of variation obtained in the 25 diabetics, plotted against the duration of the disease. The stippled lines indicate the medians

ciation was not influenced by the age of the patients.

The mean coefficient of variation in the diabetic group averages 22 (range 5-61), and differs signifi-

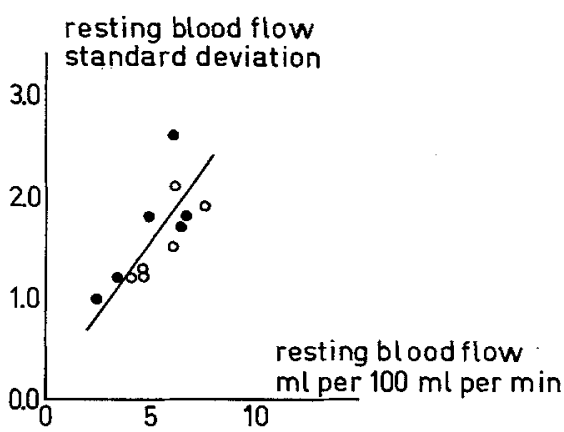

Fig. 5. Variability of the resting blood flow expressed as the standard deviation, plotted against the mean resting blood flow ( $\mathrm{ml}$ per $100 \mathrm{ml}$ foot per min). Two series of resting blood flow measurements were obtained in three newly-diagnosed patients during metabolic derangement ( ) and after normalization of the blod sugar (o). The calculated regression line obtained in the non-diabetic group is also shown

For further statistical analysis presented below, the values of the coefficient of variation were converted according to the following equation.

$$
z=100 \log \text { coefficient of variation. }
$$

Fig. 5 shows the variability of the resting blood flow in the three newly diagnosed patients studied during metabolic derangement (•) and after normaliza- 
tion of the blood sugar (o). The regression line obtained in the non-diabetic group has also been plotted. It can be seen that there is no striking difference in the two situations, despite the fact that some impairment of nervous function could be demonstrated during uncontrolled conditions [33].

Blood flow response during reactive hyperaemia. Fig. 6 shows an example of the time course of the

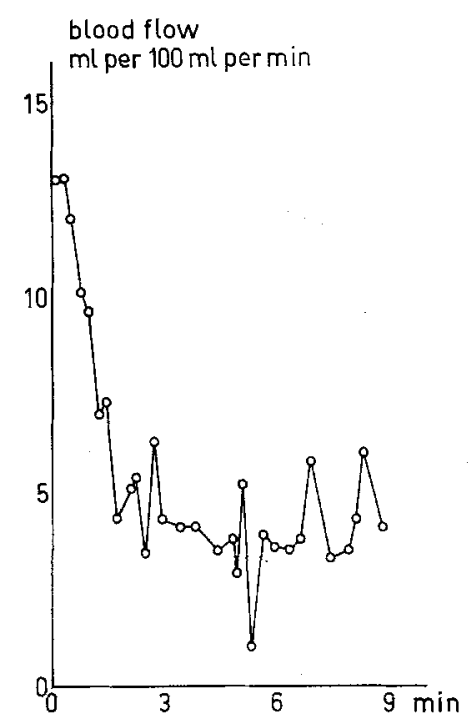

Fig. 6. Blood flow ( $\mathrm{ml}$ per $100 \mathrm{ml}$ foot per min) obtained after release of arterial acclusion (reactive hyperaemia plotted against time. Results obtained in a non-diabetic are shown (Case No. 8). Note spontaneous variations in the latter part of the 9 min period

reactive hyperaemia obtained in a non-diabetic (Case No. 8). The blood flow was high immediately after release of the arterial occlusion, and then rapidly decreased towards basal levels. Spontaneous variations are seen in the latter part of the $9 \mathrm{~min}$ period.

In the control group the maximal blood flow ranged between 12.1 and $19.3 \mathrm{ml}$ per $100 \mathrm{ml}$ foot per min, and averaged $14.1 \mathrm{ml} \pm 2.1$. The maximal blood flow increased with increasing mean resting blood flow. The equation of the regression line is:

$$
y=1.12 x+9.96 \quad(P \text { less than } 0.002) .
$$

The peak flow, which was calculated by subtracting the mean resting blood flow from the maximal blood flow, averaged $10.4 \mathrm{ml} \neq 1.4$, and ranged between $8.4 \mathrm{ml}$ and $13.7 \mathrm{ml}$ per $100 \mathrm{ml}$ foot per min. The peak flow was independent of the resting blood flow $(P$ greater than 0.1), as the regression coefficient above is close to one. For this reason the peak flow was used in the analysis presented below.

In the diabetic group the peak flow ranged between $0.6-13.7 \mathrm{ml}$ per $100 \mathrm{ml}$ foot per min. and averaged $7.8 \mathrm{ml} \pm 3.6$. Considering only the patients with a duration of the disease less than 20 years, the peak flow was of the same order of magnitude as in the non-diabetic group ( $P$ greater than 0.1 ). However after
20 years of diabetes the peak flow was often considerably reduced. Fig. 7 shows the relationship between the peak flow and the duration of the disease. Regression analysis was carried out with duration of the disease and age of the patient as the invariables, and the peak flow as the variable. However, only the first factor, the duration of diabetes, is of importance ( $P$ less than 0.001). The equation of the regression line is:

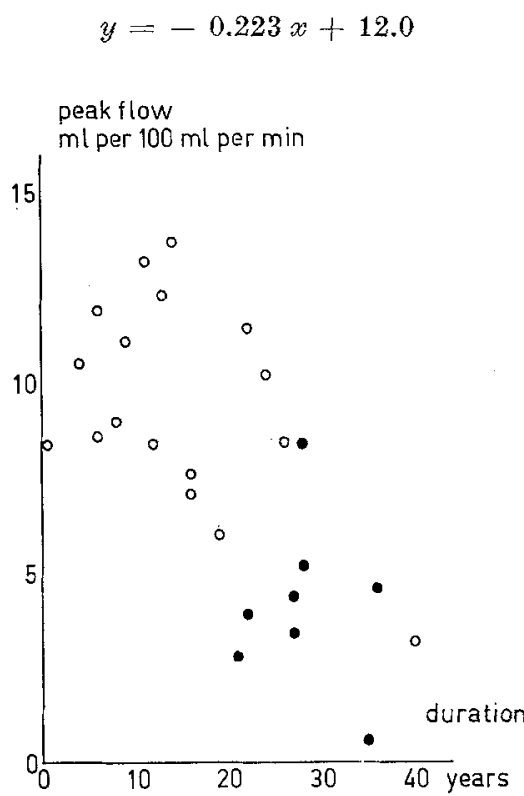

Fig. 7. Peak flow ( $\mathrm{ml}$ per $100 \mathrm{ml}$ foot per min) obtained in the 25 diabeties plotted against the duration of the disease. The symbol $(\bullet)$ denotes the presence of severe arterial calcification

The mean peak flow differs significantly from the corresponding mean in the control group ( $P$ less than $0.01)$.

Vibratory perception threshold. The vibratory perception threshold measured in the big toe increases, as is well known [33, 19,14, 11], with increasing duration of diabetes. To obtain linearity and constant standard deviation for regression analysis, the results from the examination of the threshold were converted according to the following equation: $z=100 \log$ threshold. The transformation used elsewhere [11] was found to be less satisfactory for the present data.

The equation of the regression line is:

$$
y(z)=1.08 x+110.8
$$

and the regression coefficient differs significantly from zero ( $P$ less than 0.05 ). The vibratory perception threshold could not be shown to be associated with the age of the patients in the present small series. The mean threshold in the non-diabetic group was 10 and in the diabetic group 25, a significant difference ( $P$ less than 0.001, Mann-Whitney $U$ test).

Interrelationships between variability of the resting blood flow, peak flow and the vibratory perception treshold. It is obvious from a theoretical point of view, that the 
decrease in the variability of the resting blood flow in the diabetic patients can be due to lesions of autonomic nerves, as well as to a decreased reactivity of the vessels themselves. It appears from Table 1 that the coefficient of variation is invariably reduced when the vibratory perception threshold is high. The association is illustrated in the upper part of Fig. 8. Furthermore,

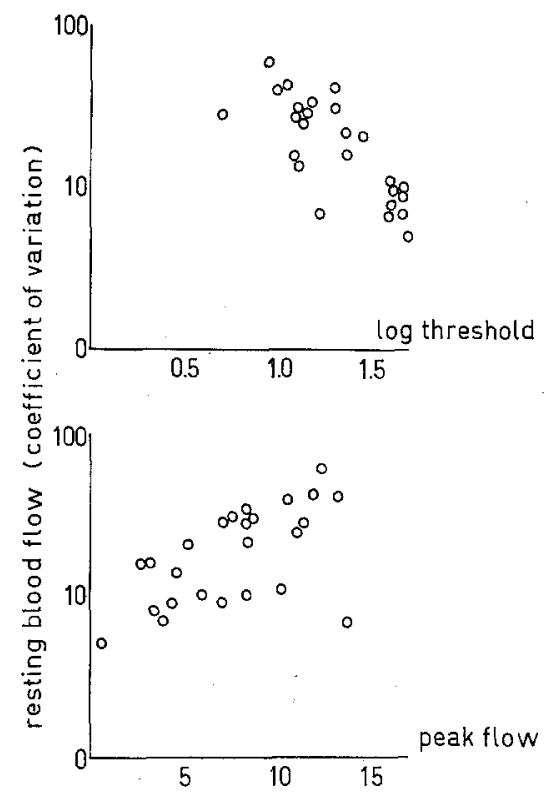

Fig. 8. The variability of the resting blood flow in diabetic patients expressed as the coefficient of variation, plotted on a log scale against the logarithm of the vibratory perception threshold (upper curve) and against the pealk flow (lower curve)

it appears from the table that the low variability in some patients (e.g. Case No. $23,38,41$ ) can only be explained on the basis of a rigidity of the vessels. The lower part of Fig. 8 illustrates the relationship between the peak flow and the coefficient of variation. The conditions are, however, complicated by the fact that all three parameters are dependent on the duration of diabetes. For this reason multiple regression analysis was carried out. The converted values of the coefficient of variation were taken as the variable, and the converted values of the vibratory perception threshold, the peak flow and the duration of the disease were used as the invariables.

The equation of the regression line is:

$y(z)=-0.73 x$ (threshold) $+2.93 x$ (peak flow) $-0.07 x$ (duration) +197.1

The two partial regression coefficients associating the coefficient of variation and the vibratory perception threshold, and associating the coefficient of variation and the peak flow differ significantly from zero ( $P$ less than $0.001,0.05$ ), whereas the duration of the disease is without significance in this analysis. The total variance is 22381, and the explained variance 15973 . When only the vibratory perception threshold and the dura- tion of the disease were used as the invariables in the analysis, the explained variance is $\mathbf{1 4 4 9 4}$. This difference is significant $(F=4.845, P$ less than 0.05$)$. It is thus established that the association between the coefficient of variation and the threshold, as well as between the coefficient of variation and the peak flow, is due to an agreement in the individual patients and not to the common dependence of the duration of diabetes.

The final solution is:

$y(z)=-0.74 x$ (threshold) $+3.05 x$ (peak flow) +198.1 ( $P$ less than $0.001,0.01$ )

The interpretation of the results is that the decrease in the variability of the blood flow is due to autonomic neuropathy as well as to a decreased reactivity of the vessels themselves.

Other features. Pulsation in the dorsal pedal artery and the posterior tibial artery. Pulsation in the two arteries was absent in two diabetics (Case No. 2 and 36 ), and pulsation of the dorsal pedal artery could not be felt in one non-diabetic (Case No. 12). In all other cases strong pulsation was felt without difficulty in both arteries.

Blood pressure. In the non-diabetic group the mean systolic pressure averaged $124 \mathrm{~mm} \mathrm{Hg} \pm 17$. In the diabetic group the mean systolic pressure averaged $140 \mathrm{~mm} \mathrm{Hg} \pm 24$. This difference is significant ( $P$ less than 0.05 ). The diastolic pressure averaged $80 \mathrm{~mm} \mathrm{Hg}$ \pm 11 in the non-diabetics and $87 \mathrm{~mm} \mathrm{Hg} \pm 13$ in the diabetics. This difference is not significant. No association could be established between the blood pressures and the duration of diabetes.

Calcification of the arteries. X-ray films of the arteries of the foot were obtained in all diabetics except one case (No. 14). The results are given in Table 1. Extensive calcification, i.e. calcification in several parts of the arterial system of the foot, has been denoted by a $X$. In Fig. 7, the symbol (.) indicates the presence of severe calcification. Minor calcification was present in a few patients and localized to a small area of one of the arteries. The present study did not include a sufficient number of persons, to allow an exact statistical analysis of the interrelationships between decreased peak flow, the presence or absence of calcification of the arteries and the duration of diabetes. This problem has been evaluated in another investigation [11]. It appears, however, from the figure and the table that extensive calcification of the arteries is associated with a small peak flow, and a low peak flow is associated with the presence of extensive calcification in all cases except one. The results are thus in accordance with those presented elsewhere [11].

$X$-ray examination was generally not performed in the non-diabetic group. However, in a $X$-ray study of the arteries of the foot in 36 non-diabetics, 25 males [11] and 11 females [34] with a comparable age, it was found that only one person, a man 32 years of age, showed minor calcification in the first interdigital space. 
The type of calcification present in the arteries of the foot is calcification of the media in all cases [11, $22,16]$

\section{Discussion}

Comments on the spontaneous variations. The usually occuring spontaneous variations in blood flow and blood volume in the distal portions of the extremities have been studied by several authors, and a review has recently been given by ABramson [1].

BuRtor [9] showed that the periodic changes in blood flow were due to changes in the activity of the sympathetic nervous system, and occured simultaneously in various parts of the vascular system. Accordingly, spontaneous variations are not noted in sympathectomized patients [9]. It cannot, however, be excluded that some minor rhythmic activity is due to local activity of smooth muscle, independent of innervation [20]. The variations are called spontaneous because they occur without any obvious external or psychical stimulus [10]. It was already noted by BURToN [9] that the changes in blood volume were to some extent independent of changes in blood flow, indicating that some of the changes in volume are due to changes in the tonus of the postcapillary vessels. A similar conclusion has been reached by other workers $[2,8]$. Despite a considerable amount of work, the significance of the spontaneous variations is not known $[1,9,8]$.

The variability of the resting blood flow in the foot found in the present study in the non-diabetic group was of the same order of magnitude as that found by Allwood [5]. A coefficient of variation lower than 20 is generally not observed in younger patients when the local temperature is kept constant about $32^{\circ} \mathrm{C}$.

Neurovascular abnormalities in diabetics. It has been known for some time that diabetic patients, particularly patients with a long duration of disease, manifest certain neurovaseular abnormalities, i.e., the normally occuring vascular responses mediated through the autonomic nervous system cannot be provoked.

One of the best known and most extensively studied neurovascular abnormalities in diabetics is the lack of rise in cutaneous temperature during indirect heating $[26,23,7,30,4]$. Although the presence of this abnormality in diabetics and its association with the duration of the disease has been established, the pathophysiological basis has never been elear. A vascular lesion, an autonomic neuropathy or both have periodically been claimed responsible [23, 7, 30, 4, 24, 25, 28]. There are probably several reasons for this state of inconsistency. First of all, conflicting results may be due to the fact that some of the methods of measuring blood flow used by the authors mentioned above, do not give a reliable estimate of the actual size of the blood flow, e.g. identical cutaneous temperature does not necessarily indicate identical cutaneous blood flow $[23,28,15]$. Another source of error might be due to erroneous interpretation of the results obtained after nerve blocking [26, 7, 24, 25]. A lack of vascular dilatation after appropriate nerve blocking does not imply a vascular lesion per se, but might as well be due to a preexisting autonomic neuropathy. It might be mentioned here that there was no association in the present study between the vibratory perception threshold, which was shown to indicate the presence or absence of autonomic neuropathy, and the mean resting blood flow, i.e. the blood flow was not increased in patients with impaired autonomic innervation. This finding is in accordance with the well known fact that the resting blood flow is not increased or only slightly increased in limbs some time after sympathectomy. Even if the vessels themselves were normal in the diabetic patients, a normal response to nerve blocking could not be expected.

The present study shows that a loss of spontaneous variations in the resting blood flow is a characteristic finding in many diabetic patients, and could be explained by the existence of an autonomic neuropathy as well as of a vascular lesion. It is likely that the same twofold mechanism is the basis of the lack of rise in cutaneous temperature during indirect heating.

Comments on the reactive hyperaemia in diabetic patients. The vascular response to ischaemia occurs in skin and muscles. Arterio-venous anastomoses are apparently not involved [17]. The response is mediated locally in the tissue concerned, and the response is not dependent on the integrity of the sympathetic nervous system $[21,3,13,18]$. The observation presented here, the decrease of peak flow with increasing duration of diabetes mellitus is in accordance with the results presented elsewhere [11], demonstrating that the maximal blood flow in the anterior tibial muscle measured by radioactive xenon ${ }^{133}$ is abnormally low in long term diabetics. Since the blood pressure was normal or slightly elevated in these patients, the abnormality is due to an increased peripheral resistance.

A rather peculiar phenomenon is the association between low peak flow as well as low maximal blood flow [11], and the presence of arterial calcification of the media. The presence of this type of calcification per se in non-diabetic persons seems generally to be accepted as an innocent finding without any functional significance, and occuring independent of intimal change $[22,27,31,12,29]$. The established association in diabetic persons between medial calcification and decreased peak flow, does suggest a somewhat different development of the peripheral vascular disease in diabetics and non-diabetics; although the calcification per se might contribute little to the increased peripheral resistance.

\section{References}

1. Abramson, D.I.: Circulation in the extremities, $p$. 207-212. New York and London: Academic Press 1967.

2. -, and K.H. Katzenstein: Spontaneous volume 
changes in the extremities. Amer. Heart. J. 21, $191-$ 198 (1941).

3. - -, and E.B. FerRIs: Observations on reactive hyperemia in various portions of the extremities. Amer. Heart J. 22, 329-341 (1941).

4. Aagenas, Ö.: Neurovascular examinations on the lower extremities in young diabetics. Copenhagen: Thesis 1962.

5. ALLWood, M. J.: Blood flow in the foot and calf in the elderly, a comparison with that in young adults. Clin. Sci. 17, 331-338 (1958).

6. - , and H.S. BuRRY: The effect of local temperature on blood flow in the human foot. J. Physiol. (Lond.) 124, 345-357 (1954).

7. BARANY, F.R.: Abnormal vascular reactions in dia. betes mellitus. Acta med. scand. suppl. 304 (1955).

8. Burch, G.E.: Digital pre- and postcapillary vaso. constriction and vasodilatation resembling pre- and postglomerular arteriolar function in the kidney. Proc. Soc. exp. Biol. (N. Y.) 102, 400-402 (1959).

9. Burton, A.C.: The range and variability of the blood flow in the human fingers and the vasomotor regulation of the body temperature. Amer. J. Physiol. 127, $437-453(1939)$

10. - , and R.M. TAYLOR: A study of the adjustment of peripheral vascular tone to the requirements of the regulation of body temperature Amer. J. Physiol. 129, $565-577(1940)$.

11. Christensen, N.J.: Muscle blood flow, measured by xenon ${ }^{133}$ and vascular calcifications in diabetics. Acta med. scand. 183, 449-459 (1968).

12. Dietrich, K.: Beiträge zur Pathologie der Arterien des Menschen. I. Mitteilung: Die allgemeine Pathologie der großen muskelosen Arterien. Virchows Arch. path. Anat. 274, 452-527 (1930).

13. Ercrina, L. W., and R.W. Wrukms: Blood flow to the forearm and calf. II. Reactive hyperemia: Factors influencing the blood flow during the vasodilatation following ischaemia. Bull. Johns Hopk. Hosp. 68, $450-476$ (1941).

14. FAgerberg, S.-E.: Diabetic neuropathy. A clinical and histological study on the significance of vascular affections. Göteborg: Thesis 1959.

15. Felder, D., E. Russ, H. Montgomery, and $O$. HoRwrtz: Relationship in the toe of skin surface temperature to mean blood flow measured with a plethysmograph. Clin. Sci. 13, 251-257 (1954).

16. FerRIER, T.M. : Radiologically demonstrable arterial calcification in diabetes mellitus. Aust. Ann. Med. 13, $222-228$ (1964).

17. Folkow, B.: Circulat. Res. 15, suppl. 1, 78 (1964).

18. Fremman, N.E.: The effect of temperature on the rate of blood flow in the normal and in the sympathectomized hand. Amer. J. Physiol. 113, $384-398$ (1935).
19. GreGersen, G.: Vibratory perception threshold and motor conduction velocity in diabetics and non-diabetics. Acta med. scand. 183, 61-65 (1968).

20. Hertzman, A.B., and J.B. Duxlon : Selective vascular reaction patterns in the nasal septum and skin of the extremities and head. Amer. J. Physiol. 127, 671-684 (1939)

21. LEwIS, T., and R.T. Grant: Observations upon reactive hyperemia in man. Heart 12, 73-120 (1925).

22. LINDBom, A. : Arteriosclerosis and arterial thrombosis in the lower limb. A roentgenological study. Acta radiol. suppl. 80, (1950).

23. Martin, M.M.: Involvement of autonomic nervefibers in diabetic neuropathy. Lancet $1953 \mathrm{I}, 560-565$.

24. Megibow, R.S., S.J. Megibow, H. Pollach, J.J. BOOKMAN, and K. OssERMan : Mechanism of accelerated peripheral vascular sclerosis in diabetes mellitus. Amer. J. Med. 15, 322-329 (1953).

25. Mendlowitz, M.: Digital Circulation, p. 103. New York 1954.

26. - E.B. Grossman, and S. AlPert : Decreased hallucal circulation, early manifestation of vascular disease in diabetes mellitus. Amer. J. Med. 15, 316-321 (1953).

27. Mitchell, J.R.A., and C.J. Schwartz: Arterial disease. Oxford 1965 .

28. Moorhouse, J.A., S.A. CARTER, and J. Doupe: Vascular responses in diabetic peripheral neuropathy. Brit. med. J. 1966 I, $883-888$.

29. Sappington, S.W., and J.A. HornefF: Tibial artery changes in comparison with those of the radial and coronary arteries. Amer. J. med. Sci. 201, 862-871 (1941).

30. Sigroth, K.: Reflex vasodilatation of fingers in the study of peripheral vascular disorders. With special references to diabetes mellitus. Gothenburg: Thesis 1957.

31. Stlmerrt, S., and H.I. LippmanN: Mønckeberg's ar. teriosclerosis. J. amer. med. Ass. 151, 1176-1179 (1953).

32. Stead, E.A., Jr., and P.A. Kunkel: A plethysmographic method for the quantitative measurement of the blood flow in the foot. J. clin. Invest. 17, 711-714 (1938).

33. Streiness, I.: Diabetic neuropathy. Vibration sense and abnormal tendon reflexes in diabetics. Acta med. scand. 173, suppl. 394 (1963).

34. Unpublished results.

\section{Dr. N.J. CHRISTENSEN}

Second Clinic of Internal Medecine Kommunehospitalet

Århus University School of Medicine

Århus, Denmark 